\title{
The effect of migration within the European Union/ European Economic Area on the distribution of tuberculosis, 2007 to 2013
}

V Hollo ${ }^{1}$, SM Kotila ${ }^{1}$, C Ködmön ${ }^{1}$, P Zucs $^{1}$, MJ van der Werf ${ }^{1}$

1. European Centre for Disease Prevention and Control (ECDC), Stockholm, Sweden

Correspondence: Vahur Hollo (vahur.hollo@ecdc.europa.eu)

Citation style for this article:

Hollo V, Kotila SM, Ködmön C, Zucs P, van der Werf MJ. The effect of migration within the European Union/European Economic Area on the distribution of tuberculosis, 2007 to 2013. Euro Surveill. 2016;21(12):pii=30171. DOI: http://dx.doi.org/10.2807/1560-7917.ES.2016.21.12.30171

Article submitted on 10 March 2015 / accepted on 04 January 2016 / published on 24 March 2016

Immigration from tuberculosis (TB) high-incidence countries is known to contribute notably to the TB burden in low-incidence countries. However, the effect of migration enabled by the free movement of persons within the European Union (EU)/European Economic Area (EEA) on TB notification has not been analysed. We analysed TB surveillance data from 29 EU/EEA countries submitted for the years 2007-2013 to The European Surveillance System. We used place of birth and nationality as proxy indicators for native, other EU/EEA and non-EU/EEA origin of the TB cases and analysed the characteristics of the subgroups by origin. From $2007-2013$, a total of 527,467 TB cases were reported, of which 129,781 (24.6\%) were of foreign origin including 12,566 (2.4\%) originating from EU/EEA countries other than the reporting country. The countries reporting most TB cases originating from other EU/EEA countries were Germany and Italy, and the largest proportion of TB cases in individuals came from Poland $(n=1,562)$ and Romania $(n=6,285)$. At EU/ EEA level only a small proportion of foreign TB cases originated from other EU/EEA countries, however, the uneven distribution of this presumed importation may pose a challenge to TB programmes in some countries.

\section{Introduction}

The epidemiology of communicable diseases can be affected by migration; between 2007 and 2011, around $40 \%$ of HIV cases in the European Union (EU) and European Economic Area (EEA) were reported among migrants [1] [2] [3]. Migration from high-incidence countries (defined as incidence as $\geq 20$ tuberculosis (TB) cases/100,000 inhabitants/year) is known to contribute notably to TB burden in low-incidence countries ( 20 TB cases/100,000 inhabitants/year) using the thresholds previously proposed by the Wolfheze working group [4] and adopted in the EU monitoring framework [5] [6-14]. Persons with latent TB infection as well as patients with active TB and multidrug-resistant
(MDR) TB can easily move from one country to another in the EU.

The free movement of persons within the EU is a fundamental right guaranteed to EU citizens by the Treaties [15]. Before 2010, the migration flows within the EU/ EEA were mainly from eastern European Member States to Member States in the south and west [16] [17]. Driven by the economic crisis, from 2007 onwards, an increase was seen in numbers of people migrating from the countries most heavily affected by the depression (Greece, Spain, Italy, Ireland and Portugal) to western and northern EU countries [16]. In 2013, 17.7 million EU citizens were living in an EU country other than their country of birth, corresponding to $3.5 \%$ of the total population [18]. The highest number of migrants from other EU countries resided in Germany $(3,635,265$; $4.4 \%$ of the total population) and the lowest in Estonia $(13,238 ; 1.0 \%$ of the total population). Possible crossborder transmission of communicable diseases as a consequence of free movement of persons across the borders has raised concerns in some countries $[19,20]$.

To our knowledge, the effect of migration within the EU/EEA on the epidemiology of TB has not been analysed previously. The objective of this study was therefore to estimate the extent of cross-border movement of TB cases within the EU/EEA. In addition, we aimed to characterise the 'foreign' TB cases originating from other EU/EEA countries, and to identify possible major patterns with respect to countries from which cases originate and which countries report such cases. Our quantitative descriptive analysis of the EU/EEA-wide TB surveillance data by geographical origin of cases may support decisions to implement targeted TB prevention and control measures where needed.

\section{Methods}

We carried out a descriptive analysis of all TB cases reported to The European Surveillance System (TESSy) 


\section{FIGURE 1}

Proportions of tuberculosis cases by origin in the EU/ EEA, 2007-2013

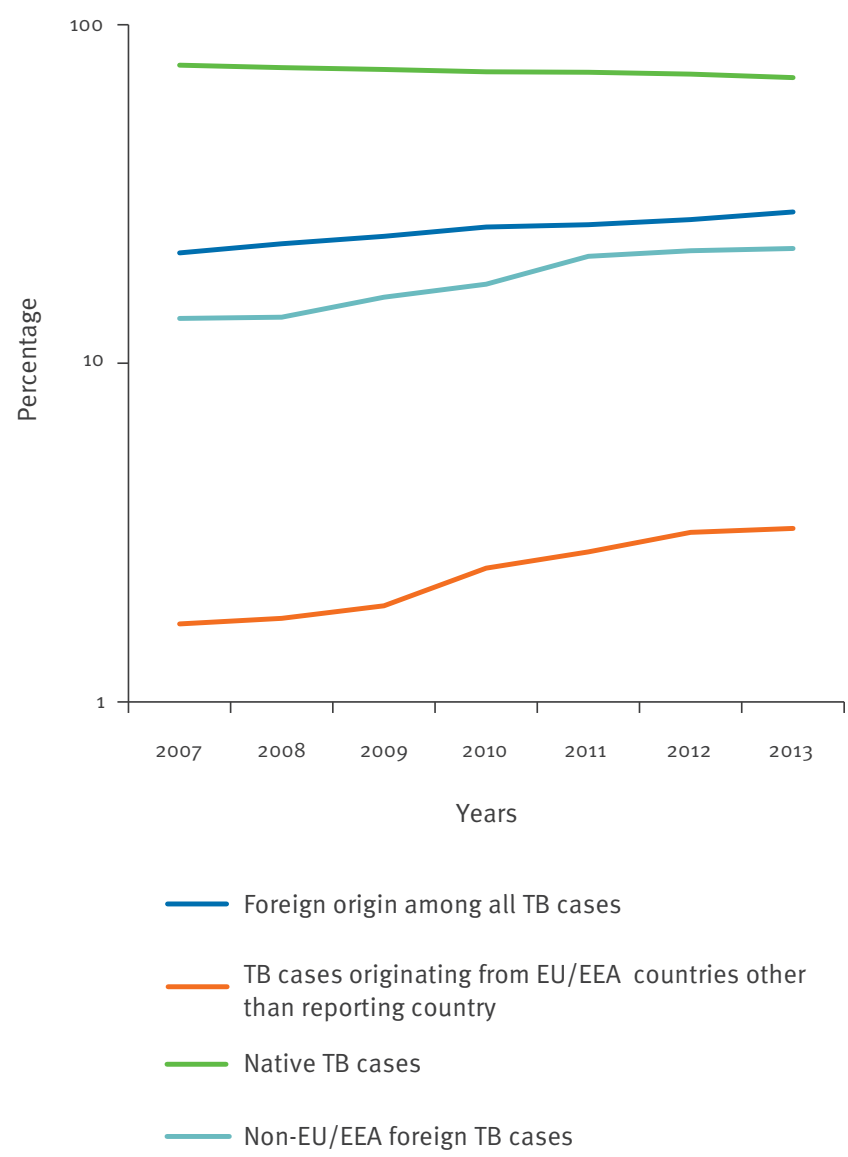

EEA: European Economic Area; EU: European Union; TB: tuberculosis.

by national surveillance institutes in $27 \mathrm{EU}$ and two EEA countries from 2007 to 2013. Data collection methods and definitions are described elsewhere [21]. Liechtenstein reported TB surveillance data to TESSy only in 2007 and Croatia joined the EU in July 2013, so both countries were excluded from the analysis.

After submission to TESSy, data are subjected to automated checks for completeness and accuracy followed by expert-driven manual data validation. For the calculation of notification rates, country population denominators were obtained from Eurostat (www.epp. eurostat.ec.europa.eu) [18]. Notification rates for 'foreign TB cases' of EU/EEA origin and non-EU/EEA origin, and for the native population were calculated only for 2013 due to incomplete historical population data stratified by area of origin from Eurostat [18].

\section{Definition of native and foreign tuberculosis cases}

For Austria, Belgium, Greece, Hungary and Poland, we used citizenship to assign geographic origin, for the remaining 24 countries place of birth was used as a proxy indicator for the geographic origin of a TB case.

\section{FIGURE 2}

Tuberculosis notification rates in low ${ }^{\mathrm{a}}$ - and highincidence ${ }^{b}$ EU/EEA countries by subgroup of origin, 2013

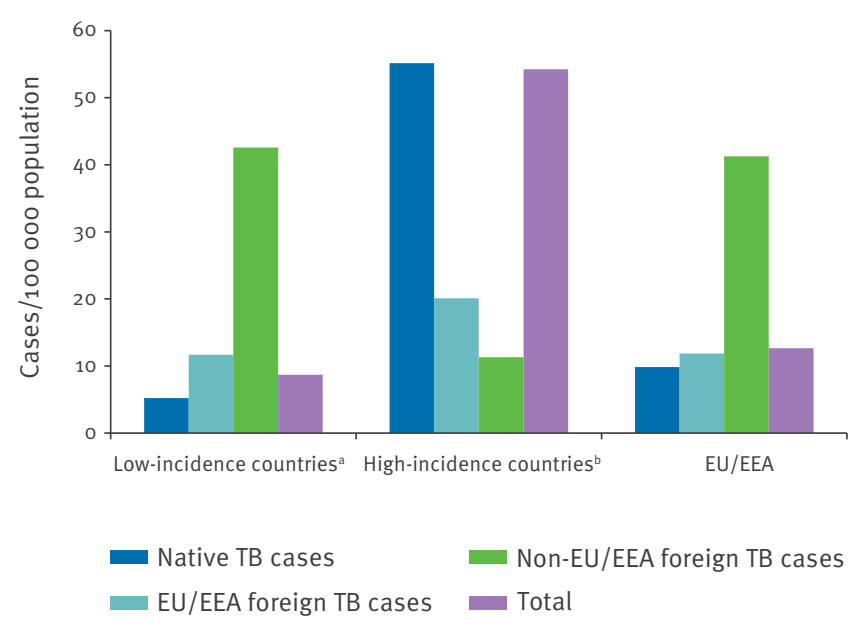

EEA: European Economic Area; EU: European Union; TB: tuberculosis.

Low-incidence countries are defined as having an incidence $<20$ TB cases per 100,000 inhabitants per year, and high-incidence countries as having an incidence $\geq 20$ TB cases per 100,000 inhabitants per year, using the thresholds previously proposed by the Wolfheze working group [4] and adopted in the EU monitoring framework [5].

a Low TB incidence countries: Austria, Belgium, Cyprus, Czech Republic, Denmark, Finland, France, Germany, Greece, Hungary, Iceland, Ireland, Italy, Luxembourg, Malta, the Netherlands, Norway, Poland, Slovakia, Slovenia, Spain, Sweden and United Kingdom.

b High TB incidence countries: Bulgaria, Estonia, Latvia, Lithuania, Portugal and Romania.

A 'native TB case' was defined as a TB case reported by the patient's country of birth or citizenship, and a 'foreign TB case' as a case reported by a country different from the patient's country of birth or citizenship. The foreign cases were further divided into cases originating from outside of the EU/EEA and cases from other EU/EEA countries. Cases defined as 'foreign' but with missing country of origin, were excluded from the analysis. Cases originating from countries that do not exist any longer i.e. 'Soviet Union', 'Yugoslavia', 'Czechoslovakia' were recoded as 'foreign, country not specified'. TB cases originating from Greenland and Faroe Islands were considered as native Danish cases, and the cases originating from Jersey and Gibraltar were classified as native cases of the United Kingdom (UK).

\section{Data analysis}

We analysed the data by age and sex, site of disease, previous treatment, laboratory confirmation, and drug susceptibility testing results for the two main firstline anti-TB drugs (isoniazid and rifampicin), HIV coinfection and treatment success 12 months after start of treatment. The distribution of these variables was stratified by origin, excluding the unknowns where 
Tuberculosis cases originating from other EU/EEA countries by reporting EU/EEA country and tuberculosis cases reported by other EU/EEA countries by country of origin, 2007-2013

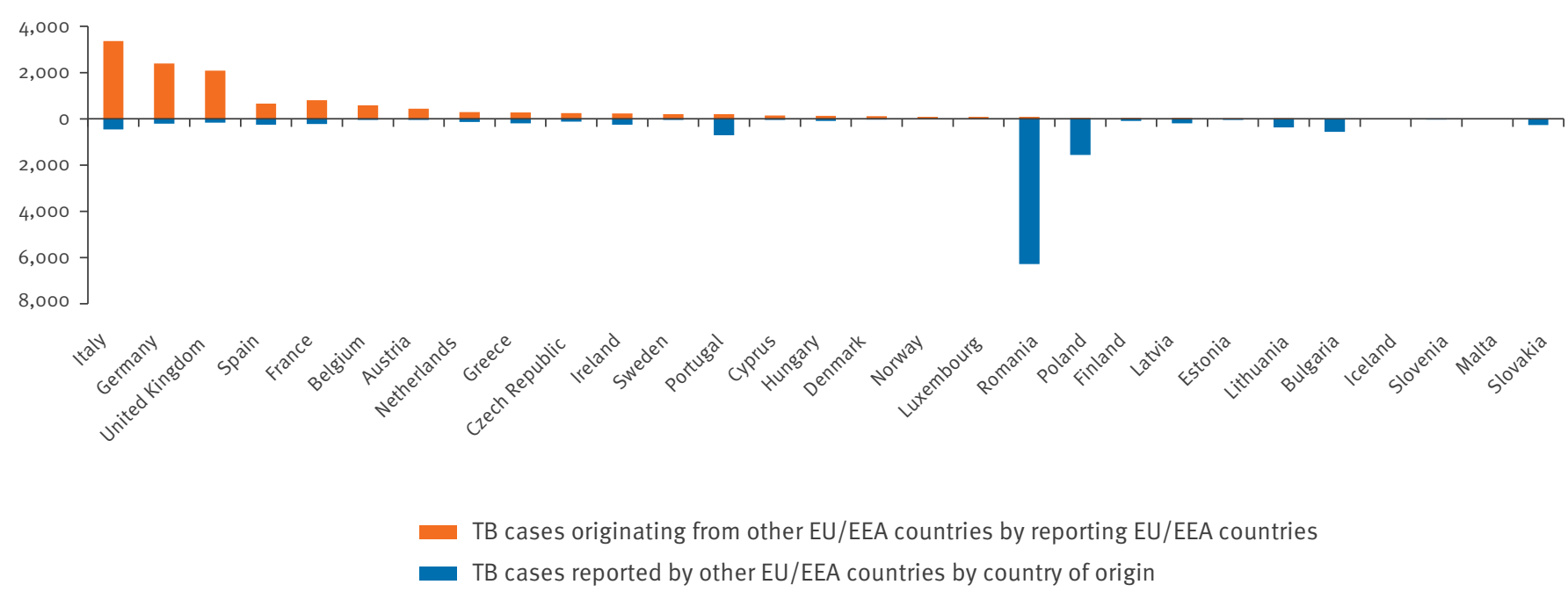

EEA: European Economic Area; EU: European Union.

applicable. In a sensitivity analysis, we excluded all native cases reported by Romania and Poland. Both countries accounted for large shares of native cases and foreign cases reported by other EU/EEA countries while hardly reporting any cases of other EU/EEA origin themselves. The exclusion of Romanian and Polish native cases was thus meant to identify and avoid any potential bias resulting from largely comparing foreign and native cases from these two countries.

To compare incidence levels, countries were grouped as high- and low-incidence TB countries based on the data reported for 2013. Thus, high-incidence countries were six countries: Bulgaria, Estonia, Latvia, Lithuania, Portugal and Romania, and low-incidence countries all other EU/EEA countries.

For data analysis, we used Stata 13 (StataCorp LP, College Station, Texas, US) and Microsoft Excel 2010. Chi-squared tests were used to analyse differences between percentages. A p value of less than 0.01 was considered as statistically significant.

\section{Results}

During the period 2007 to 2013 , a total of 527,467 TB cases (notification rate $14.9 / 100,000$ ) were reported of which 11,788 cases $(2.2 \%)$ were reported as 'origin unknown'. Of these cases with unknown origin, 11,595 (98.4\%) were reported from countries defining origin by country of birth and 193 (1.6\%) from countries defining origin by citizenship. Of the remaining 515,679 cases, $385,898(74.8 \%)$ were reported as native and $129,781(25.2 \%)$ as foreign. Among foreign cases, 121,994 (94.0\%) were defined by country of birth and $7,787(6.0 \%)$ by citizenship. Country of origin was reported for 104,491 (80.5\%) of all foreign cases whereas $25,290(19.5 \%)$ foreign cases were reported without country of birth/citizenship. Country-specific proportions of foreign TB cases with country of origin reported ranged from $0.1 \%(213 / 147,843)$ in Romania to $85.7 \%(2,090 / 2,438)$ in Norway. The vast majority, $91,925(88.0 \%)$ of foreign TB cases with known origin came from outside the EU/EEA. In total, 12,566 cases (2.4\% of all TB cases and $9.7 \%$ of foreign TB cases) were reported to originate from another EU/EEA country. Country-specific proportions of foreign TB cases of EU/EEA origin varied between $0.05 \%(9 / 18,365)$ in Bulgaria and 36.6\% (136/372) in Cyprus (Table 1). Most of the foreign TB cases of EU/EEA origin were diagnosed in Italy $3,368(12.2 \%$ of all cases reported in Italy), Germany $(2,388 ; 7.7 \%)$ and the UK $(2,089$; $3.5 \%$ ). The proportion of TB cases originating from another EU/EEA country was reported to be below $1 \%$ in seven countries (Bulgaria, Latvia, Lithuania, Poland, Romania, Slovakia and Slovenia); 1 up to $10 \%$ in 18 countries (Austria, Belgium, Czech Republic, Denmark, Estonia, Finland, France, Germany, Greece, Hungary, Ireland, Malta, the Netherlands, Norway, Portugal, Spain, Sweden and UK) and more than 10\% in Cyprus, Iceland, Italy and Luxembourg.

Even though the overall TB notification rate declined by $5 \%$ annually from 2007 to 2013 , the number of foreign TB cases from other EU/EEA countries increased from $1,428(1.7 \%$ of all TB cases) in 2007 to $2,093(3.3 \%)$ in $2013(p<0.01)$, while the overall number of foreign TB cases increased from $17,809(21.2 \%)$ in 2007 to 18 $011(28.0 \%)$ in 2013 (Figure 1). In the same period, the number of cases with unknown origin decreased from $2,384(2.8 \%)$ to $1,407(2.2 \%)$. 
TABLE 1

Total numbers and notification rates of tuberculosis cases per 100,000 population and percentage of cases of foreign origin and foreign EU/EEA origin, 2007-2013

\begin{tabular}{|c|c|c|c|c|c|c|c|}
\hline Country & $\begin{array}{l}\text { Total number } \\
\text { of notified } \\
\text { TB cases }\end{array}$ & $\begin{array}{l}\text { TB notification } \\
\text { rate per } \\
100,000\end{array}$ & $\begin{array}{l}\text { Number of TB } \\
\text { cases originating } \\
\text { from outside } \\
\text { the reporting } \\
\text { country }\end{array}$ & $\begin{array}{l}\text { Percentage of } \\
\text { foreign origin }\end{array}$ & $\begin{array}{l}\text { Number of notified } \\
\text { TB cases in persons } \\
\text { originating from } \\
\text { other EU/EEA } \\
\text { countries }^{\mathrm{a}}\end{array}$ & $\begin{array}{l}\text { Percentage } \\
\text { of foreigners } \\
\text { originating from } \\
\text { other EU/EEA } \\
\text { countries }\end{array}$ & $\begin{array}{l}\text { Percentage of } \\
\text { EU/EEA foreign } \\
\text { cases among } \\
\text { all cases }\end{array}$ \\
\hline Austria & 5,058 & 8.6 & 2,119 & 41.9 & 440 & 20.8 & 8.7 \\
\hline Belgium & 7,065 & 9.3 & 3,595 & 50.9 & 581 & 16.2 & 8.2 \\
\hline Bulgaria & 18,365 & $35 \cdot 3$ & 44 & 0.2 & 9 & 20.5 & 0.05 \\
\hline Cyprus & 372 & 6.5 & 301 & 80.9 & 136 & 45.2 & 36.6 \\
\hline Czech Republic & 4,771 & 6.5 & 884 & 18.5 & 242 & 27.4 & 5.1 \\
\hline Denmark & 2,597 & 6.7 & 1,560 & 60.1 & 108 & 6.9 & 4.2 \\
\hline Estonia & 2,592 & 27.7 & 441 & 17.0 & 27 & 6.1 & 1.0 \\
\hline Finland & 2,289 & 6.1 & 574 & 25.1 & 33 & 5.7 & 1.4 \\
\hline France & 36,632 & 8.1 & 17,547 & 47.9 & 799 & 4.6 & 2.2 \\
\hline Germany & 31,197 & 5.4 & 14,360 & 46.0 & 2,388 & 16.6 & 7.7 \\
\hline Greece & 3,966 & 5.1 & 1,601 & 40.4 & 269 & 16.8 & 6.8 \\
\hline Hungary & 10,165 & 14.7 & 228 & 2.2 & 133 & 58.3 & 1.3 \\
\hline Iceland & 82 & 3.7 & 55 & 67.1 & 9 & 16.4 & 11.0 \\
\hline Ireland & 3,003 & 9.5 & 1,295 & 43.1 & 225 & 17.4 & 7.5 \\
\hline Italy & 27,695 & 6.6 & 13,684 & 49.4 & 3,368 & 24.6 & 12.2 \\
\hline Latvia & 7,019 & 47.3 & 385 & 5.5 & 33 & 8.6 & 0.5 \\
\hline Lithuania & 14,067 & 64.5 & 360 & 2.6 & 24 & 6.7 & 0.2 \\
\hline Luxembourg & 232 & 6.6 & 144 & 62.1 & 78 & 54.2 & 33.6 \\
\hline Malta & 292 & 10.1 & 233 & 79.8 & 6 & 2.6 & 2.1 \\
\hline $\begin{array}{l}\text { The } \\
\text { Netherlands }\end{array}$ & 7,048 & 6.1 & 5,005 & 71.0 & 295 & 5.9 & 4.2 \\
\hline Norway & 2,438 & 7.2 & 2,090 & 85.7 & 85 & 4.1 & 3.5 \\
\hline Poland & 55,709 & 20.8 & 345 & 0.6 & 36 & 10.4 & 0.1 \\
\hline Portugal & 19,336 & 26.6 & 2,709 & 14 & 201 & 7.4 & 1.0 \\
\hline Romania & 147,843 & 104.4 & 213 & 0.1 & 78 & 36.6 & 0.1 \\
\hline Slovakia & 3,405 & 9.0 & 48 & 1.4 & 8 & 16.7 & 0.2 \\
\hline Slovenia & 1,261 & 8.8 & 341 & 27 & 9 & 2.6 & 0.7 \\
\hline Spain & 49,222 & 15.2 & 15,058 & 30.6 & 662 & 4.4 & 1.3 \\
\hline Sweden & 4,163 & 6.4 & 3,518 & 84.5 & 195 & 5.5 & 4.7 \\
\hline UK & 59,583 & 13.7 & 41,044 & 68.9 & 2,089 & 5.1 & 3.5 \\
\hline Total & 527,467 & 14.9 & 129,781 & 24.6 & 12,566 & 9.7 & 2.4 \\
\hline
\end{tabular}

EEA: European Economic Area; EU: European Union; TB: tuberculosis; UK: United Kingdom.

a Data on country of origin not reported from years 2007 to 2010 by France, and from 2008 and 2009 by Portugal.

Compared with native TB cases, cases from other EU/ EEA countries were more frequently female, 15 to 44 years old and affected by pulmonary TB. Their previous treatment, culture result and treatment outcome were less commonly known, and they were less frequently successfully treated. In contrast, they were more frequently tested for susceptibility to TB drugs than native cases, but found to have $38 \%$ less MDR TB. Finally, compared with native TB cases, cases from other EU/ EEA countries were $60 \%$ less frequently tested for HIV co-infection; those tested, however, were not significantly more often HIV-positive than native cases (Table 2).
A statistically significant difference $(p<0.01)$ between the native cases and TB cases originating from other EU/EEA countries was seen for all the clinical and microbiological characteristics except for the proportions of cases with unknown site of disease and the proportions of HIV-positive cases.

Excluding Romanian and Polish native cases from this analysis made no difference to these findings. 
Notification rates by geographical origin of tuberculosis cases

Of the 64,327 TB cases notified in 2013, 44,909 $(69.8 \%)$ were native TB cases, providing a notification rate of 9.8 per 100,000 for the native population. Of the total number of foreign cases, $14,050(21.8 \%)$ were reported among foreigners originating from outside of the EU/EEA (notification rate 41.3/100,000 population), and 2,093 (3.3\%) among foreigners originating from the EU/EEA outside of the reporting country (notification rate $11.9 / 100,000$ population).

The vast majority, 2,015 (96.3\% of all foreign cases from EU/EEA countries), of foreign TB cases originating from the EU/EEA, were reported in low-incidence countries and only $78(3.7 \%)$ were registered in high-incidence EU countries in 2013. As illustrated in Figure 2, in 2013 the notification rate per 100,000 migrant population with EU/EEA origin was 20.1 for high-incidence countries, which is about one third of the notification rate among the native population (55.2), and almost two times higher than the notification rate among foreigners coming from outside the EU/EEA (11.3). The notification rate of 11.7 per 100,000 population observed in low-incidence countries among foreigners originating from the EU/EEA is twice as high as among the national population (5.2), and less than one third of the notification rate of TB cases coming from outside of EU/EEA (42.6) (Figure 2).

\section{Country of origin of tuberculosis cases with foreign EU/EEA origin}

TB cases originating from other EU/EEA countries, originated from 29 different countries: 6,285 cases (50.0\%) from Romania, 1,562 (12.4\%) from Poland, 704 (5.6\%) from Portugal, 563 (4.5\%) from Bulgaria, and 458 (3.6\%) from Italy (Figure 3).

At the EU/EEA level, the seven-year average proportion of cases originating from other EU/EEA countries was $2.4 \%$, but in some countries the share was much higher, reaching up to $36.6 \%$ of all TB cases reported in Cyprus during 2007 to2013, 33.6\% in Luxembourg, $11.0 \%$ in Iceland and $12.2 \%$ in Italy (Table 1). A vast majority (92.5\%) of TB cases from other EU/EEA countries reported by Italy originated from Romania, the country with the highest burden of TB in the EU/EEA.

\section{Discussion}

Our results show that only $3.3 \%(2,093 / 64,327)$ of TB cases notified in the EU/EEA in 2013 originated from other EU/EEA countries. This roughly matches the 3.5\% of all persons residing in the EU that originated from other EU countries in 2013 [18]. Therefore, free movement between countries within the EU/EEA does not seem overall to cause disproportionate challenges for TB prevention and control in the EU/EEA.

Throughout the study period, the proportion of foreign TB cases originating from other EU/EEA countries slowly increased from 1.7 to $3.3 \%$ of all TB cases, while the percentage of native TB cases declined from $76.0 \%$ to $69.8 \%$. There were notable differences between the numbers of TB cases originating from the respective countries and 'foreign TB cases' from EU/EEA reported by them. The migration flow of TB cases was mainly from TB high-incidence countries to low-incidence countries. This is expected since the TB burden is divided unevenly across the EU [22]. In 2007 to 2013, Germany, Italy and the UK reported most foreign TB cases from other EU/EEA countries and Bulgaria, Poland and Romania were the countries from which most TB cases from EU/EEA countries reported by other EU/EEA countries originated. In 2013, the EU countries with the largest population of EU immigrants were France, Germany and the UK [18] and the EU countries with the highest numbers of emigrants were Poland, Romania and Spain [23]. We do not see a clear pattern in the size of the migrant population from other EU/EEA countries and the number of foreign TB cases from other EU/EEA countries. This is expected as TB in migrants does not only depend on the size of the migrant population but also on the TB incidence in the country of origin and other factors such as living conditions of migrant populations and mixing patterns [14]. In general, the level of TB transmission is not high between groups of different ethnic origin in the EU/EEA [24], however, it is not known whether this applies to the migrants originating from the other EU/EEA countries.

Our study design entails some limitations. In the absence of data indicating in which country the infection was contracted, we used the country of birth and citizenship as proxy indicators for origin of the TB cases. This might have led to under- or overestimation of the case numbers in the subgroups by geographical origin, for example if native cases actually got infected abroad, or if foreign cases were infected in their current country of residence. In addition, the comparability of data between countries is compromised by three factors: not all countries have reported all data for the whole period 2007 to 2013; the method of reporting differs between countries; and some reporting practices applied by individual countries, e.g. relating to origin, previous treatment, drug susceptibility testing and treatment outcome are not consistent over time. For the descriptive analysis presented here, possible interactions between parameters like sex ratio and age distribution of migrants have not been taken into account. Finally, under-reporting of TB may have led to an underestimation of TB burden. Recent studies from England [25], Greece [26] and regions within Italy [27], the Netherlands [28], Romania [29] and Spain [30] have estimated under-reporting to range between $15 \%$ and $80 \%$. One of these studies, however, found that underreporting applied less to migrants than the native population (18\% vs 68\%) [27].

Our results show that drug susceptibility testing results were available more frequently for foreign TB cases of EU/EEA origin than native cases. This is supported by the fact that the main countries reporting TB cases in 
TABLE 2

Comparison of native and foreign tuberculosis cases originating from within or outside of the EU/EEA, 2007-2013

\begin{tabular}{|c|c|c|c|c|c|c|c|}
\hline & \multirow{2}{*}{\multicolumn{2}{|c|}{ Native cases }} & $p$-value ${ }^{b}$ & \multicolumn{4}{|c|}{ Foreign cases } \\
\hline & & & \multicolumn{2}{|c|}{ EU/EEA origin } & \multicolumn{2}{|c|}{ non-EU/EEA origin } & \multirow[b]{2}{*}{$\%$} \\
\hline & $\mathrm{N}$ & $\%$ & & $N$ & $\%$ & $\mathrm{~N}$ & \\
\hline Total & 385,898 & 73.2 & $<0.01$ & 12,566 & 2.4 & 91925 & 17.4 \\
\hline \multicolumn{8}{|l|}{ Sex } \\
\hline Female & 130,124 & 33.7 & $<0.01$ & 4.638 & 36.9 & 38,580 & 42.0 \\
\hline Male & 255,523 & 66.2 & $<0.01$ & 7,891 & 62.8 & 53,122 & 57.8 \\
\hline Unknown & 251 & 0.1 & $<0.01$ & 37 & 0.3 & 223 & 0.2 \\
\hline \multicolumn{8}{|l|}{ Age groups } \\
\hline $0-14$ & 17,499 & 4.5 & $<0.01$ & 506 & 4.0 & 2,601 & 2.8 \\
\hline $15-24$ & 37,285 & 9.7 & $<0.01$ & 1880 & 15.0 & 14,741 & 16.0 \\
\hline $25-44$ & 116,386 & 30.2 & $<0.01$ & 6040 & 48.1 & 48,683 & 53.0 \\
\hline $45-64$ & 132,046 & 34.2 & $<0.01$ & 2748 & 21.9 & 17,611 & 19.2 \\
\hline$\geq 65$ & 82,331 & 21.3 & $<0.01$ & 1349 & 10.7 & 8,157 & 8.9 \\
\hline Unknown & 351 & 0.1 & $<0.01$ & 43 & 0.3 & 132 & 0.1 \\
\hline \multicolumn{8}{|l|}{ Site of disease } \\
\hline Pulmonary & 322277 & 83.5 & $<0.01$ & 10850 & 86.3 & 53111 & 57.8 \\
\hline Extrapulmonary & 63025 & 16.3 & $<0.01$ & 1686 & 13.4 & 38463 & 41.8 \\
\hline Unknown & 596 & $0.2^{c}$ & $p=0.02$ & 30 & $0.2^{c}$ & 351 & 0.4 \\
\hline \multicolumn{8}{|l|}{ Previous treatment ${ }^{d}$} \\
\hline No & 308,126 & 79.8 & $<0.01$ & 8,371 & 66.6 & 70,386 & 76.6 \\
\hline Yes & 57,822 & 15.0 & $<0.01$ & 891 & 7.1 & 5,721 & 6.2 \\
\hline Unknown & 19,950 & 5.2 & $<0.01$ & 3,304 & 26.3 & 15,818 & 17.2 \\
\hline \multicolumn{8}{|l|}{ HIV infectione } \\
\hline HIV tested & 81,518 & 21.1 & $<0.01$ & 1,060 & 8.4 & 5,876 & 6.4 \\
\hline HIV infected ${ }^{f}$ & 3,634 & 4.5 & $p=0.03$ & 62 & 5.8 & 567 & 9.6 \\
\hline \multicolumn{8}{|l|}{ Culture result } \\
\hline Positive & 238,373 & 61.8 & $<0.01$ & 8,099 & 64.5 & 56,766 & 61.8 \\
\hline Negative & 80,066 & 20.7 & $<0.01$ & 1,261 & 10.0 & 8,321 & 9.1 \\
\hline Unknown & 67,459 & 17.5 & $<0.01$ & 3,206 & 25.5 & 26,838 & 29.2 \\
\hline DST result total & 325,278 & NA & NA & 7,737 & NA & 71,386 & NA \\
\hline Test performed ${ }^{g}$ & 141,097 & 43.4 & $<0.01$ & 5,419 & 70 & 46,393 & 65.0 \\
\hline MDR-TB & 8,450 & 6.0 & $<0.01$ & 200 & 3.7 & 1,356 & 2.9 \\
\hline Cohort 2007-2012 total & 340,989 & NA & NA & 10,417 & NA & 77,845 & NA \\
\hline Treatment outcome reported & 298,464 & 87.5 & $<0.01$ & 6,618 & 63.5 & 63,600 & 81.7 \\
\hline Treatment success ${ }^{\mathrm{h}}$ & 223,323 & 74.8 & $<0.01$ & 4,449 & 67.2 & 49,256 & 77.4 \\
\hline
\end{tabular}

DST: drug susceptibility testing; EEA: European Economic Area; EU: European Union; HIV: human immunodeficiency virus, MDR: multidrugresistant; NA: not applicable; TB: tuberculosis; UK: United Kingdom.

${ }^{a}$ Origin (native/foreign) was not reported for 11,788 (2.2\% from all reported) cases and country of origin was not specified for 25,290 ( $4.8 \%$ from all reported) cases.

${ }^{\mathrm{b}}$ Comparing EU/EEA foreigners and native TB cases.

' Real percentage of unknown site information for foreign cases of EU/EEA origin is 0.24 and for native cases 0.15 .

dEquals previous treatment history (reported as ‘previous diagnosis' by Belgium, Denmark, Ireland, Norway, Sweden (2007) and the UK).

${ }^{\mathrm{e}}$ TB cases reported by countries that reported only HIV-positive cases are excluded from the nominator.

${ }^{f}$ Percentages based on HIV-tested cases.

${ }^{\mathrm{g}}$ Percentage of cases tested for drug susceptibility to isoniazid and rifampicin among all culture-positive cases, excluding countries who did not report case-based DST data.

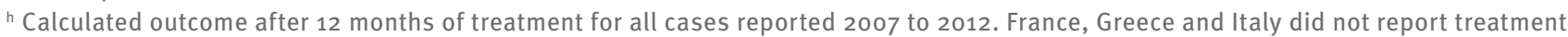
outcome results and are excluded from the treatment outcome analysis. 
migrants of EU/EEA origin report higher proportions of drug susceptibility testing than the main countries reporting native cases, Romania and Poland. In 2007 to 2013, the proportion of MDR-TB was lower among foreign cases originating from other EU/EEA countries than in native cases. Also, of all MDR-TB cases reported by low-incidence countries of the EU/EEA, less than $10 \%$ originated from other EU/EEA countries. This implies that migration within the EU/EEA is not the main driver of MDR-TB incidence in low-incidence EU/ EEA countries.

The mean age of foreign TB cases of EU/EEA origin was lower than among the native TB cases. It is not surprising that most of the foreign TB cases of EU/EEA origin occur within the population at working age considering that the most frequent factor influencing the decision to migrate in the EU is employment [16], followed by family reunion, study and retirement. The proportion of culture-positive and of pulmonary cases was higher among migrants from EU/EEA countries than among natives. This could possibly be explained by migrants having a higher threshold for seeking healthcare in a foreign country and the challenge of accessing healthcare in a foreign country, leading to a delayed diagnosis and more advanced disease.

We noted that the completeness of data on TB treatment history was exceptionally low and the treatment outcome 12 months after start of treatment was less frequently reported for foreign cases originating from other EU/EEA countries compared with native cases and cases from non-EU/EEA countries. Persons diagnosed with TB in another EU/EEA country may decide to return to their country of origin for treatment. In this case the treatment outcome may not be made available to the country that diagnosed the case. The issues in cross-border exchange of TB case information have been identified before $[31,32]$, and the need for facilitated referral and exchange of information between EU/EEA countries is evident.

In conclusion, the uneven distribution of TB diagnosed in persons originating from other EU/EEA countries within the EU/EEA may pose an incentive for coordinated EU action to improve TB programmes in individual countries. Awareness of the number of cases deriving from specific EU high-incidence countries can facilitate targeted TB prevention and control efforts in receiving countries, optimally in collaboration with the TB cases' countries of origin. In all EU/EEA countries, however, the number of TB cases from non-EU/ EEA countries was higher than the number of foreign TB cases originating from other EU/EEA countries [33], implying that TB control efforts addressing migrant populations should primarily focus on migrants coming from TB-endemic regions outside of the EU/EEA.
Acknowledgements

The authors acknowledge the nominated national operational contact points for tuberculosis Peter Henrik Andersen, Delphine Antoine, Trude Margrete Arnesen, Thorsteinn Blondal, Domnica Ioana Chiotan, Edita Davidavičienė, Irene Demuth, Raquel Duarte, Sabine Erne, Walter Haas, Alexander Indra, Jerker Jonsson, Ourania Kalkouni, Maria Koliou, Maria Korzeniewska-Kosela, Gábor Kovács, Joan O’Donnell, Analita Pace Asciak, Maria Grazia Pompa, Elena Rodríguez Valín, Alexandar Simuniovic, Erika Slump, Hanna Soini, Ivan Solovič, Petra Svetina, Lucy Thomas, Tonka Varleva, Piret Viiklepp, Kate Vulāne, Jiři Wallenfels and Maryse Wanlin (names are in alphabetical order) for providing the surveillance data used in this analysis.

No specific sources of funding were used for this study. The authors performed the study as part of their job at ECDC.

\section{Conflict of interest}

None declared.

\section{Authors' contributions}

Vahur Hollo coordinated the data analysis, wrote the manuscript and contributed to the study design. Saara Magdalena Kotila drafted parts of the manuscript, contributed to the revision of the manuscript and data analysis. Csaba Ködmön contributed to the data analysis and study design. Phillip Zucs contributed to the study design, data analysis and the manuscript writing. Marieke Johanna van der Werf contributed to the design of the study, interpreted the results and revised the manuscript.

\section{References}

1. European Centre for Disease Prevention and Control (ECDC). Technical Report. Assessing the burden of key infectious diseases affecting migrant populations in the EU/EEA. Stockholm: ECDC; 2014. Available from: http://ecdc.europa. eu/en/publications/Publications/assessing-burden-diseasemigrant-populations.pdf.

2. European Asylum Support Office (EASO). Annual report on the situation of asylum in the European Union 2014. EASO: 2015. Available from: https://easo.europa.eu/wp-content/uploads/ EASO-Annual-Report-2014.pdf

3. Cousins S. Experts sound alarm as Syrian crisis fuels spread of tuberculosis. BMJ. 2014;349:g7397. Available from: http:// www.bmj.com/content/bmj/349/bmj.g7397.full.pdf.

4. World Health Organization, International Union Against Tuberculosis and Lung Disease, and Royal Netherlands Tuberculosis Association Working Group,Broekmans JFMG, Migliori GB, Rieder HL, Lees J, Ruutu P, Loddenkemper R, et al. European framework for tuberculosis control and elimination in countries with a low incidence. Recommendations of the World Health Organization (WHO), International Union Against Tuberculosis and Lung Disease (IUATLD) and Royal Netherlands Tuberculosis Association (KNCV) Working Group.Eur Respir J. 2002;19(4):765-75. DOI: 10.1183/09031936.02.00261402 PMID: 11999007

5. European Centre for Disease Prevention and Control (ECDC). Progressing towards TB elimination. Stockholm: ECDC; 2010. Available from: http://ecdc.europa.eu/en/publications/ Publications/101111_SPR_Progressing_towards_TB_ elimination.pdf

6. Baussano I, Mercadante S, Pareek M, Lalvani A, Bugiani M. High rates of Mycobacterium tuberculosis among socially marginalized immigrants in low-incidence area, 1991-2010, Italy. Emerg Infect Dis. 2013;19(9):[1437-45. Available from: http://www.ncbi.nlm.nih.gov/pubmed/23965807

7. Kruijshaar ME, Abubakar I, Stagg HR, Pedrazzoli D, Lipman M. Migration and tuberculosis in the UK: targeting screening for latent infection to those at greatest risk of disease. Thorax. 2013;68(12):1172-4. Available from: http://www.ncbi.nlm.nih. gov/pubmed/23828120. 
8. Molina-Salas Y, de las Mercedes Lomas-Campos M, RomeraGuirado FJ, Romera-Guirado MJ. Influence of migration on tuberculosis in a semi-urban area. Arch Bronconeumol. 2014;50(8):325-31. Available from: http://www.ncbi.nlm.nih. gov/pubmed/24629758.

9. Monge-Maillo B, Jimenez BC, Perez-Molina JA, Norman $F$, Navarro $M$, Perez-Ayala $A$, et al. Imported infectious diseases in mobile populations, Spain. Emerg Infect Dis. 2009;15(11):[1745-52. Available from: http://www.ncbi.nlm.nih. gov/pubmed/19891861

10. Padovese V, Egidi AM, Melillo TF, Farrugia B, Carabot P, Didero $D$, et al. Prevalence of latent tuberculosis, syphilis, hepatitis $B$ and $C$ among asylum seekers in Malta. J Public Health. 2014;36(1)22-7. Available from: http://www.ncbi.nlm.nih.gov/ pubmed/23559596

11. Vasileva K. Nearly two-thirds of the foreigners living in EU Member States are citizens of countries outside the EU27. Statistics in focus, 31/2012. Eurostat, Luxembourg: European Commission; 2012. Available from: http://www. trf.sll.se/Global/Dokument/Statistik/externa_rapporter/ eurostat_2012_31_foreigners_in_the_eu.pdf

12. Minion J, Gallant V, Wolfe J, Jamieson F, Long R. Multidrug and extensively drug-resistant tuberculosis in Canada 19972008: demographic and disease characteristics.PLoS One. 2013;8(1):e53466. DOI: 10.1371/journal.pone.0053466 PMID: 23326436

13. Mor Z, Pinsker G, Cedar N, Lidji M, Grotto I. Adult tuberculosis in Israel and migration: trends and challenges between 1999 and 2010. Int J Tuberc Lung Dis. 2012;16(12):1613-8. Available from: http://www.ncbi.nlm.nih.gov/pubmed/23131258

14. Olson NA, Davidow AL, Winston CA, Chen MP, Gazmararian JA, Katz DJ. A national study of socioeconomic status and tuberculosis rates by country of birth, United States, 19962005. BMC Public Health. 2012;12:365. Available from: http:// www.ncbi.nlm.nih.gov/pubmed/22607324

15. Consolidated version of the Treaty on the Functioning of the European Union Official Journal. Official Journal of the European Union. Luxembourg: Publications Office of the European Union. C 326, 26.10.2012: p. 0001-0390 (2012). Available from: http://eur-lex.europa.eu/legal-content/EN/TXT/ PDF/?uri=CELEX:12012E/TXT\&from =EN

16. Benton M, Petrovic M. How free is free movement? Dynamics and drivers of mobility within the European Union. Brussels: Migration Policy Institute Europe, 2013.

17. Abel GJ, Sander N. Quantifying global international migration flows. Science. 2014;343(6178):1520-2. Available from: http:// www.ncbi.nlm.nih.gov/pubmed/24675962

18. Eurostat. Population by sex, age group and country of birth. Last update: 21 Aug 2014. Eurostat: Luxembourg; 2014. Available from: http://ec.europa.eu/eurostat

19. Bernitz BK. Communicable disease policy development in response to changing European political frontiers in Finland, Norway and Sweden. Scand J Public Health. 2008;36(8):875-8. Available from: http://www.ncbi.nlm.nih. gov/pubmed/19004906

20. Gonzalo X, Hutchison DC, Drobniewski FA, Pimkina E, Davidaviciene E. Multidrug-resistant tuberculosis in the United Kingdom and Lithuania.Int J Tuberc Lung Dis. 2014;18(6):663-5. DOI: 10.5588 /ijtld.13.0342 PMID: 24903935

21. Europe EW. Tuberculosis surveillance and monitoring in Europe 2014. Available from: http://www.ecdc.europa.eu/ en/publications/_layouts/forms/Publication_DispForm. aspx? List $=4 \mathrm{f} 55$ ad $51-4$ aed -4 d32-b960-af70113 dbb90\&ID=1050

22. European Centre for Disease Prevention and Control (ECDC) / WHO Regional Office for Europe. Tuberculosis surveillance and monitoring in Europe, 2015. Stockholm: ECDC; 2015. Available from: http://ecdc.europa.eu/en/publications/Publications/ tuberculosis-surveillance-monitoring-Europe-2015.pdf

23. Eurostat. Emigration by five year age group, sex and country of next usual residence. Eurostat: Luxembourg; 2014. [Updated 5 Dec 2014]. Available from: http://ec.europa.eu/eurostat

24. Sandgren A, Schepisi MS, Sotgiu G, Huitric E, Migliori GB, Manissero D, et al. Tuberculosis transmission between foreignand native-born populations in the EU/EEA: a systematic review. Eur Respir J. 2014;43(4):1159-71. Available from: http:// www.ncbi.nlm.nih.gov/pubmed/24114966

25. VAN Hest NA, Story A, Grant AD, Antoine D, Crofts JP, Watson JM. Record-linkage and capture-recapture analysis to estimate the incidence and completeness of reporting of tuberculosis in England 1999-2002. Epidemiol Infect. 2008;136(12):160616. Available from: http://www.ncbi.nlm.nih.gov/ pubmed/18346285

26. Lytras T, Spala G, Bonovas S, Panagiotopoulos T. Evaluation of tuberculosis underreporting in Greece through comparison with anti-tuberculosis drug consumption.PLoS One. 2012;7(11):e50033. DOI: 10.1371/journal.pone.0050033 PMID: 23185524

27. Melosini L, Vetrano U, Dente FL, Cristofano M, Giraldi M, Gabbrielli L, et al. Evaluation of underreporting tuberculosis in Central Italy by means of record linkage. BMC Public Health. 2012;12(1):472. DOI: 10.1186/1471-2458-12-472 PMID: 22897910

28. van Hest NA, Smit F, Baars HW, De Vries G, De Haas PE, Westenend PJ, et al. Completeness of notification of tuberculosis in The Netherlands: how reliable is recordlinkage and capture-recapture analysis? Epidemiol Infect. 2007;135(6):1021-9. Available from: http://www.ncbi.nlm.nih. gov/pubmed/17156496

29. Cojocaru C, van Hest NA, Mihaescu T, Davies PD. Completeness of notification of adult tuberculosis in Iasi County, Romania: a capture-recapture analysis. Int J Tuberc Lung Dis. 2009;13(9):1094-9. Available from: http://journals.plos.org/ plosone/article?id=10.1371/journal.pone.0050033

30. Gimenez-Duran J, Galmes-Truyols A, Gonzalez-Cortijo T, Bosch-Isabel C, Nicolau-Riutort A, de Mateo-Ontanon S. Estimated incidence of tuberculosis by capture-recapture in the Balearic Islands, 2010-2012. Int J Tuberc Lung Dis. 2014;18(11):1357-62. Available from: http://www.ncbi.nlm.nih. gov/pubmed/25299871

31. European Centre for Disease Prevention and Control (ECDC). Healthcare system factors influencing treatment results of patients with multidrug-resistant tuberculosis. Stockholm: ECDC; 2014 . Available from: http://www.ecdc.europa.eu/ en/publications/Publications/mdr-tb-healthcare-factorsinfluencing-treatment-results.pdf

32. Wolfheze Transborder Migration Task Force,Dara M, de Colombani P, Petrova-Benedict R, Centis R, Zellweger IP, Sandgren A, et al. . Minimum package for cross-border TB control and care in the WHO European region: a Wolfheze consensus statement.Eur Respir J. 2012;40(5):1081-90. DOI: 10.1183/09031936.00053012 PMID: 22653772

33. Ködmön C, van der Werf M, Zucs P. Migration-related tuberculosis: epidemiology and characteristics of tuberculosis cases originating outside the European Union and European Economic Area, 2007 to 2013. Euro Surveill. 2016;21(12): pii=30164. DOI: http://dx.doi.org/10.2807/15607917.ES.2016.21.12.30164

\section{License and copyright}

This is an open-access article distributed under the terms of the Creative Commons Attribution (CC BY 4.0) Licence. You may share and adapt the material, but must give appropriate credit to the source, provide a link to the licence, and indicate if changes were made.

This article is copyright of the authors, 2016. 